Sís SOMOS AMIERICANOS

Revista de Estudios

Transfronterizos
Volumen XIX, número 1,

enero-junio 2019.

Recibido: 30 de julio de 2018.

Aprobado: 1 de mayo de 2019.

\title{
El libre tránsito de Bolivia a través de Chile: controversias y gasto económico chileno. 2005-2011*
}

\author{
Free transit from Bolivia through Chile: disputes and Chilean economic expenditure. \\ 2005-2011 \\ Loreto Correa $^{* *}$ \\ Academia Nacional de Estudios Políticos y Estratégicos (ANEPE), Chile.
}
Cómo citar este artículo: Correa, L. (2019). El libre tránsito de Bolivia a través de Chile: controversias y gasto económico chileno. 2005-2011. Si Somos Americanos, 19(1),
pp.111-138.
DOI: $10.4067 / \mathrm{S} 0719-09482019000100111$

\section{Resumen}

Este artículo, elaborado sobre la base de observaciones en las actas del Comité de Fronteras Binacional del período 2005-2011, y de las estadísticas oficiales del Instituto Boliviano de Comercio Exterior, explica el funcionamiento actual del libre tránsito en el marco del Tratado de 1904 firmado entre Chile y Bolivia, poniendo en valor el trabajo conjunto realizado entre ambos países en el período. En el análisis, se demuestra la existencia permanente de un diálogo entre Estados, lo que evoluciona hacia una paulatina maritimización -entendida como la continua situación de conflicto producida durante el gobierno de Evo Morales en torno al reclamo marítimo- de las relaciones bilaterales, en la que se instala un discurso de disconformidad sobre el libre tránsito. El estudio revisa, a

* Este artículo forma parte del proyecto "Proyección de la relación chileno-boliviana. Escenarios actuales y futuros"Proyecto ANEPE 201908. Agradecemos a la Academia Nacional de Estudios Políticos y Estratégicos su financiamiento, a Carolina Palma, tesista de Ciencia Política y Relaciones Internacionales de la Universidad Alberto Hurtado, parte de la pesquisa documental y a Simón Yantani, cientista político de la Pontificia Universidad Católica de Chile por su colaboración.

**. Licenciada y magíster en Historia, Universidad de Chile; magíster en Historia Latinoamericana, Universidad Internacional de Andalucía; Doctora en Historia de las Relaciones Internacionales, Universidad San Pablo CEU de Madrid. Analista de la Academia Nacional de Estudios Políticos y Estratégicos, Santiago, Chile. Correo electrónico: lcorrea@anepe.cl 
partir de la contextualización de la firma y funcionamiento del Tratado de 1904, el libre tránsito, sus controversias, características y gasto económico chileno en la materia, dándose cuenta práctica de la gestión portuaria y de la conectividad efectiva de Bolivia hacia el Pacífico.

Palabras claves: Chile-Bolivia, libre tránsito, Tratado de 1904.

\begin{abstract}
This article, which is based on observations contained in the minutes of the Binational Borders Committee for the period 2005-2011 and official statistics issued by the Bolivian Institute of Foreign Trade, explains the current functioning of free movement under the framework of the 1904 Treaty between Chile and Bolivia, highlighting the joint work carried out by the two countries during this period. The analysis demonstrates the existence of ongoing dialogue between states, which evolves towards a gradual "maritime focus" understood as the on-going situation of conflict created during Evo Morales administration with respect to Bolivia's maritime claim - and bilateral relations in which a discourse of discontent is present regarding the issue of free transit. Based on the contextualization of the signing and functioning of the 1904 Treaty, the study reviews the disputes, characteristics and economic cost to Chile, providing a practical analysis of port management and effective connectivity between Bolivia and the Pacific Ocean.
\end{abstract}

Keywords: Chile-Bolivia, free transit, 1904 Treaty.

\title{
Introducción
}

En el marco del estudio del funcionamiento efectivo del Tratado de Paz y Amistad de 1904 y las sistemáticas críticas del gobierno de Evo Morales sobre las supuestas trabas comerciales que Chile estaría colocando a Bolivia respecto del libre tránsito, uno de los aspectos más controvertidos guarda relación con supuestos obstáculos y discriminaciones de Chile, tanto hacia las exportaciones como importaciones a Bolivia a través de puertos chilenos (La Razón, 5 de febrero de 2015). En este sentido, este trabajo, enmarcado en un proyecto de largo aliento sobre el conflicto subregional, busca responder la siguiente interrogante: ¿qué sustento empírico tienen las reclamaciones bolivianas sobre el libre tránsito?

La investigación es un estudio de caso histórico del funcionamiento del libre tránsito, condición base descrita en el Tratado de 1904 y que se contrasta con las cifras comerciales de Bolivia. Para ello se analizan las actas del Comité de Fronteras y Límites de los dos 
países, las Memorias del Ministerio de Relaciones Exteriores, y diversas actas de las reuniones del Grupo de trabajo sobre el Libre Tránsito entre los años de funcionamiento: 2005-2011. En cada una de estas fuentes se buscaron indicadores que dieran cuenta de cómo se llevaron a cabo las reuniones entre ambos países y qué se trató en ellas respecto de la carga boliviana.

Si se habla de las relaciones de Chile-Bolivia, lo primero que se aprecia es que la mayoría de los artículos poseen un método descriptivo (Becerra de la Roca, 2004; Correa, 2012; González Mansilla, 2015; González Miranda y Ovando Santana, 2014, 2016; Rodríguez Elizondo, 2009). Desde la historia, lo que más se ha trabajado son las relaciones políticas (Bustos, 2004; Ceppi, 2014; Ríos Gallardo, 1963, entre otros). Ya sea para contextualizar, o bien seguir un relato o para analizar específicamente ciertos períodos en la relación bajo el marco del Ejecutivo (Correa, 2007; Quitral Rojas, 2014). Por su parte, los estudios de Correa (2012), Concha y Garay (2013) y Orías (2004) se ocupan del retorno de la democracia en el año 1990 en Chile y los cambios hacia Bolivia en materia exterior, dando cuenta de los vaivenes producto de los cambios de enfoque de los distintos gobiernos.

En otra línea de análisis sobre el conflicto, Correa y Vera (2016) destacan históricamente el tema de la demanda marítima de Bolivia en distintos foros regionales. Lagos (2013) y diversos autores bolivianos (Guzmán Escobari, 2015; Orías, 2015) incluyen a la descripción el supuesto mal actuar de Chile en la conducción de su política exterior. Guzmán Escobari (2015), por ejemplo, siguiendo la línea del gobierno de Evo Morales -a nuestro juicio como su más fiel representante-, insiste en denunciar que el Tratado de 1904 habría sido suscrito de manera obligada (Ostria Trigo, 2008, p. 61 ${ }^{1}$; Guzmán Escobari, 2015). Este planteo "victimista" es generalizado en los autores bolivianos en el libreto asociado con el Estado Plurinacional y al Libro del Mar (DIREMAR, 2014), que sintetiza la noción de despojo.

En esta línea, sobre la cual Orías (2004) señala que Chile debería responder a las demandas de Bolivia, se sostiene que cualquier negociación bilateral para un retorno con soberanía a las costas deberá contemplar:

a. construir un nuevo entendimiento, orientado a satisfacer la necesidad de Bolivia de acceder al mar, independiente y autónomo de las circunstancias históricas anteriores a 1879 ,

b. si se ha de tratar de una nueva negociación que contemple y satisfaga el interés de ambas partes, se debe contemplar las necesarias compensaciones y

c. se deberá consultar el acuerdo previo del Perú, para el caso previsto en el Tratado de 1929, otorgando las garantías a los “derechos específicos” que ese país mantiene en Arica. (Orías, 2004, p. 51)

Más allá de cualquier visión política de las relaciones binacionales, las cifras comerciales del país expresan que Bolivia ha logrado poner en frontera, exportar e importar cuanta 
carga comercial ha tenido durante todo el siglo XX y lo que lleva del XXI. Esto es lo que el discurso del Estado Plurinacional discute, aludiendo a un supuesto deterioro del PIB por este concepto (Cambio, 17 de octubre de 2016).

De forma opuesta, Chile destaca la favorable condición que Bolivia posee tras la suscripción y ratificación del Tratado. En efecto, González Mansilla (2015) describe esta favorable condición de Bolivia sobre el tránsito por los puertos de Chile, condición particularmente beneficiosa y de la cual carecen otros países que no disponen de costas soberanas. Sin embargo, la permanente alusión a este hecho, y que supuestamente deterioraría la libertad comercial de Bolivia, resulta falaz si se observa la trayectoria comercial de este país. De esto justamente se ocupa este artículo.

La bibliografía de ambos países es generalmente concluyente en el difícil escenario para una resolución de los diversos conflictos entre las dos naciones (Molina, 2014; Ruz, 2011). Suscribimos que el panorama no es alentador. El deterioro diplomático en el marco de las estructuras de seguridad regionales, así como las instancias de descalificación verbal recientes, han dado por tierra el impulso que se dio al inicio de los años noventa, y que había avanzado hacia la construcción de medidas de confianza mutua en un auspicioso marco para la integración binacional (Correa, 2012). En ese contexto, se observa un rotundo fracaso de iniciativas complementarias, sobre todo en el ámbito de la cooperación técnica, programas conjuntos y colaboración interagencial entre ambos países.

Desde una perspectiva del contexto, Salas (2015) advierte sobre el peligro del narcotráfico en la frontera chileno-boliviana, en el período 1973-1999, y la ausencia de data hasta entrado el siglo XXI, detectándose que la producción de cocaína entre el 2000 y el 2009 había crecido un 112\%. Asimismo, García Pinzón (2015) destaca los problemas asociados con la seguridad proveniente de los resultados del trabajo del desminado fronterizo en la frontera norte. Por otra parte, los trabajos de Tapia y Chacón (2016) y Ceppi (2014) consideran complementariamente los aspectos culturales, migratorios y funcionales a la visión trifronteriza y paradiplomática.

Respecto de la metodología utilizada en los diversos estudios, en su gran mayoría se trata de análisis cualitativos, o derechamente ensayos políticos bolivianos en los que se insiste en la noción de despojo (Guzmán, 2015). En Bolivia no existen estudios cuantitativos hasta el año 2016. Los estudios económicos del Instituto Boliviano de Comercio Exterior (IBCE, 2016) ejemplifican la falacia del discurso político. A la fecha, hay tres informes que se abocan a la disminución de las exportaciones bolivianas: el informe de la Cámara de Despachantes de Aduana y el Instituto de Comercio Exterior, en el que se detalla con precisión la disminución de las exportaciones bolivianas en el período 2009-2012. En este informe, se alude a que el fenómeno ocurrió debido a la estructura exportadora y no a las supuestas trabas aduaneras o de otro tipo en el sector occidental del país (IBCE, 2012). 
El segundo informe corresponde a la inversión y el gasto nacional en materia de conectividad, destinado a la viabilidad del libre tránsito de mercancías bolivianas, realizado por Carrier, Téllez y Villamizar (2013), texto que discurre sobre una solución del tema marítimo a través del establecimiento de una zona especial, en clara homologación a lo que se ha hecho en materia internacional a partir del Tratado Antártico, olvidándose, por cierto, que la complejidad de la relación entre Chile y Bolivia ocurre en espacios habitados, equipados y vinculados con el Tratado de 1929 con Perú. Finalmente, Thomson y Bradanovich (2015) se ocupan de las inversiones de Chile en la materia, particularmente en lo que gastos en viabilidad se refiere a principios del siglo XXI.

Dentro del enfoque neoliberal, la teoría de los regímenes es útil para revisar el tema del libre tránsito (Krasner, 1983); primero, porque ha habido institucionalidad en la materia; segundo, porque a partir de ella se planteaba un diálogo particular esencial en el cumplimiento del Tratado de 1904. Compartimos que, si bien los Estados se mueven por sus propios intereses, ¿qué ocurre cuando un país, un siglo después, apunta al hecho de que las condiciones posteriores a la suscripción de un tratado ya no le favorecen? ¿Hasta qué punto resulta serio impugnar el libre tránsito, porque aparentemente operaría mal? (Hasenclever, Mayer y Rittberger, 1999) Para ello, veamos el origen mismo del Tratado de 1904.

\section{Hacia la comprensión del contexto económico de la firma del Tratado de 1904.}

A modo de recordatorio, se exponen los motivos de la firma del Tratado por parte de Bolivia.

1. La necesidad de encontrar un rápido sistema de transporte, seguro y de bajo costo entre los centros productores de materias primas y puertos de embarque constituyó uno de los principales desafíos tecnológicos, financieros y políticos que Bolivia argumentó a finales del siglo XIX (Thorp, 1998).

2. La falta de crecimiento y el modelo de desarrollo exportador condujeron a una rápida concentración de la producción minera mediante el ingreso del capitalismo internacional en las áreas de mayor demanda de producción. Es a partir de ello que tanto la Guerra del Pacífico como la Guerra Federal contribuyeron no solo a potenciar el modelo exportador, sino a la definición de objetivos estratégicos en materia internacional (Asebey y Mamani, 2015).

3. Los mercados internacionales. Para Yacsic (1997, p. 19), desde el descalabro de la economía del guano con la Guerra del Pacífico, las élites nacionales comprendieron que Bolivia no podía permanecer ajena a los mercados internacionales.

Los mineros de la plata inauguraron la presencia de 'empresarios' en el manejo directo de la administración del estado. Los gobiernos de Gregorio Pacheco (1884-1888), Aniceto 
Arce (1888-1892) y Severo Fernández Alonso (1896-1899), todos propietarios de minas, utilizaron el poder para orientar las políticas y recursos públicos hacia la satisfacción de sus intereses empresariales.

Justamente por estas razones se construyeron líneas férreas tras la Guerra del Pacífico. El antiguo mecanismo de exportaciones, ya fuera por tierra o por ríos, era insuficiente para la minería occidental del país. Así, la primera línea férrea se planteó como proyecto entre 1870 y 1914 entre Antofagasta y Oruro, bajo la gravitación de la economía del enclave minero con la idea de prioridad de exportaciones. En opinión de Yacsic (1997), la política de estos "empresarios" y sus intereses económicos asociados a capitales chilenos y británicos explican el marco histórico de la pérdida del litoral boliviano. Lo anterior es ratificado por el historiad or Reynaldo Gómez, quien afirma que la perspectiva de Aniceto Arce, impulsor de la industrialización boliviana en el siglo XIX, responde a que:

la única ruta económicamente posible y aprovechable en aquellos tiempos, era la construcción de una línea férrea desde el Puerto de Cobija o "cualquier punto del Litoral" hacia los centros mineros más importantes del país; es decir, entendía la importancia que tenían los puertos naturales del Pacífico para el desarrollo de la república. (Gómez Zubieta, 2001, p. 33)

¿Cuál es el origen del libre tránsito? La necesidad de Bolivia por poner sus minerales en el Pacífico. Para el geógrafo boliviano del siglo XIX, Pedro Aniceto Blanco, en un artículo publicado en 1910, la vialidad en Bolivia debía superar escollos gigantescos:

Bolivia, nación encerrada entre los repliegues más desarrollados del sistema central andino, sin una salida que dé fácil movimiento a su intercambio comercial, el que, lejos de gozar de independencia en su desenvolvimiento, ha tenido que soportar los resultados, no solo de esa situación que la aleja del mundo comercial, sino también de su posición topográfica que la ha colocado en medio de las mayores accidentaciones [sic] de la América del Sud. (Soux, 1999)

¿Qué prueba que la meta - de tener ferrocarriles de parte de los países sudamericanos- era la prioridad económica de los Estados? El gasto, la inversión y la cláusula de su establecimiento en todos los tratados internacionales de la época. Hoy puede parecer una exageración, pero a principios del siglo $\mathrm{XX}$, sin carreteras y con una cordillera imponente, era o tener ferrocarriles, o sumirse en el olvido en materia de comercio internacional. El "Pacto de Tregua de 1884 con Chile" es el principal argumento político que determina la nueva constitución geopolítica de la República de Bolivia, y el futuro ferrocarril construido desde Ascotán en la frontera a la población de Uyuni (Gómez Zubieta, 2001).

Que la Cordillera de los Andes era el principal escollo a sortear en la construcción de ferrocarriles en América del Sur, era un hecho, pero que ese hecho ponía a Bolivia en una situación imposible frente al erario fiscal, lo era aún más. En 1873, la Compañía de Salitres de Antofagasta tendió la primera línea férrea en territorio boliviano en el tramo que unía el 
salar El Carmen al puerto de Antofagasta. En 1885, esta empresa y la de Huanchaca firmaron un contrato para ampliar la línea, donde ambas gozarían de beneficios en las tarifas. Por ello, en 1886, la línea llegó a Calama; en 1892, hasta Oruro, y en 1899, con la participación de la Railway, el tramo de Antofagasta a Uyuni y Pulacayo-Huanchaca quedaba concluido.

Las consecuencias de la Guerra del Pacífico y la convicción de la necesidad e importancia de una conexión ferroviaria eran imprescindibles para aumentar las exportaciones de manera directa, pero también como mecanismo de la oligarquía minera, ejemplo material de un pacto político económico para mantenerse al alero del poder político, sin los costos de la presidencia y las disputas nacionales. En estos términos, los tratados internacionales de la época debían:

- Satisfacer la necesidad de ferrocarriles para la élite.

- Permitir las indemnizaciones y montos para cubrir los requerimientos de subsistencia del Estado boliviano.

El precio de este pacto era el precio del desarrollo minero. El "triunfo de la civilización", auspiciado por la burguesía nacional, tuvo en Aniceto Arce la figura central de la minería boliviana de fines del siglo XIX (Díaz, 2011).

Segunda prueba del peso de los ferrocarriles, la Guerra Federal de Bolivia. Desde principios del siglo XX, Aniceto Arce, creador del Partido Pacifista junto a Mariano Baptista, fue quien primero procedió a exigir ferrocarriles. Asumidos los liberales, dos presidentes, José Manuel Pando e Ismael Montes, tuvieron particular atención por estos temas, por mucho que luego les pesara (González Ortega, 2017).

El tren significaba para Bolivia el automático abaratamiento de los fletes de transporte hacia el demandante mercado internacional de materias primas. En ese entorno, las rivalidades y contradicciones nacionales, en medio de la discusión de la Ley de Radicatoria (1898) -que cambiaba la capital del país-, fueron claves para apurar los ferrocarriles. La Guerra Federal de 1899 dio el visto bueno a la hegemonía paceña y al "entreguismo" de las costas, que tanto pesan hoy y se omiten en la política del Estado Plurinacional.

Pero sería la Guerra del Acre, la que hacia 1900 haría el resto del trabajo. La falta de control del Estado llevaría a Bolivia a una guerra con Brasil por los territorios del Norte, donde la única salida honrosa sería apurarse en percibir una gruesa indemnización y estipular también la construcción de ferrocarriles. En efecto, cuando se pretende visualizar la firma del Tratado de Paz con Chile, aisladamente respecto del momento histórico vivido por Bolivia, se cometen dos errores. El primero es doloso, porque se pretende invocar una situación "suspendida" entre solo dos actores, Chile y Bolivia y, lo que es peor, confundirla a partir de las condiciones del Pacto de Tregua de 1883 y las fallidas negociaciones de 1895 (Concha y Garay, 2013). El segundo es culposo, al establecer una entelequia, según la lógica de Schmitt (2007), de la oposición amigo- enemigo; esto es, un país abusivo y otro 
víctima de la codicia. Esta perspectiva cambia de plano si vemos los resultados del tratado de Petrópolis de 1903, en que también se coloca la cláusula de los ferrocarriles, lo que Barragán, Lema, Mendieta y Peres-Cajías (2015) determinan como la solución a un problema interno del sistema político boliviano.

El Tratado del Acre, firmado el 17 de noviembre de 1903, especificaba una transferencia de dos millones de libras esterlinas de Brasil a Bolivia. En el diario El Tribuno de Bolivia, José Paravicini se refiere al alcance sobre el uso de esos recursos, hablando de la aparente imposibilidad del pago de varias deudas a entidades bancarias por no encontrarse en el presupuesto de la nación dicha actividad. Manifiesta que:

Concluido definitivamente el pacto de cesión de los territorios del Acre a favor de la República de Brasil, mediante su aprobación por parte del Congreso Brasilero, se cree en los círculos comerciales y bursátiles que el Gobierno de Bolivia girará próximamente sobre los fondos que debe recibir como indemnización, y aun se asegura que existen gestiones iniciadas para obtener los giros, y a la sombra de esa versión se juega a la alza sobre el tipo de cambio, ocasionando desconcierto en las operaciones de los bancos, y especialmente en las de los mineros y agricultores.

(...) Se afirma, no sé si con fundamento, que el Gobierno piensa girar por 200,000 Libras para pagar a los bancos los créditos pendientes.

Laudable sería el propósito si no estuviera en oposición a los preceptos de la Carta fundamental y las leyes que rigen nuestro sistema financiero (26 de febrero de 1904).

Pero sea que se diera esta u otra aplicación a los fondos provenientes del Brasil, la inversión solo podía hacerse con autorización legislativa mediante ley presupuestaria sancionada con ese objeto. En vísperas de las navidades de 1903, se expresaba que debía construirse el ferrocarril Madera-Mamoré por el Brasil. "Todo ese comercio tendrá grandes facilidades y economías para salir al Atlántico. Se entiende que ese ferrocarril será común en su explotación" (El Comercio de Bolivia, 16 de diciembre de 1903). ${ }^{2}$

¿Cuál es la importancia de estas expresiones y cómo se vinculan con Chile? Expresan por una parte la convicción del nivel de prioridad de las inversiones ferroviarias y, por otra, la grave situación económica de Bolivia. Asimismo, dan cuenta del importante volumen de dinero que requería la economía boliviana para su viabilidad. Sin contar con esos dineros, el Estado de Bolivia no habría tenido cómo afrontar sus gastos. Sin ese "pequeño" detalle es sencillo imputar tanto a Brasil como a Chile la responsabilidad de un "despojo". Considerando el hecho, y en atención a lo que se señala por la Comisión de Hacienda de Bolivia en el Congreso, se colocan las negociaciones en su contexto.

2 Archivo Itamaraty. Legación de Brasil en La Paz. Carpeta 1903-1907. Anexo oficio $2^{\circ}$ sección $\mathrm{N}^{\circ} 27,16$ de diciembre de 1903, nota de prensa 4, p. 2. 
Con todo, las condiciones de la firma del Tratado del Acre también son demostración de que Bolivia nunca se pensó a sí misma al margen de las indemnizaciones, y mucho menos con la posibilidad de tener un ferrocarril que consiguiera comunicar al país con las costas solo con recursos propios. Esa era la real situación del tesoro boliviano y del tránsito hacia el Pacífico.

En ese marco, las condiciones de la Paz de Petrópolis de 1903, acuerdo que pone fin a la Guerra del Acre, son tan extraordinarias como las que planteará la negociación con Chile al año siguiente. En efecto, menos de un año después, pesa nuevamente la consideración del erario fiscal a lo cual se suma la posibilidad real de la construcción de una línea en marcha de ferrocarril entre Arica y La Paz. Así, Bolivia pacta por segundo año consecutivo las indemnizaciones, la obtención de un pago extraordinario y suma así una segunda línea de tren; bases que vino a negociar a Chile personalmente su canciller Félix Avelino Aramayo en 1902, tras haber ido a informar al Imperio Británico al respecto (The Kew Gardens Archives, 28 de enero de 1902). Por ello, los tratados firmados por Bolivia no son solo un tema de fijación de fronteras, sino un instrumento de viabilidad financiera para el país a principios del siglo XX.

De acuerdo con las Memorias del Ministerio de Relaciones Exteriores de Chile del año 1902, las bases del acuerdo propuestas por el gobierno de La Paz a través de Aramayo fueron:

1. Abandono por parte de Bolivia de toda pretensión a un puerto en el Pacífico.

2. Independencia comercial de este país, quedando Chile sometido a la condición de nación más favorecida.

3. Abono por parte de Chile de una suma de dinero, entregada por anualidades, que se destinaría a la construcción de ferrocarriles que den fácil salida al Pacífico a los productos de Bolivia. (Ríos Gallardo, 1963, p. 163)

Y es justamente este último aspecto el que pone de manifiesto el espíritu jurídico que se consagra en el Tratado de 1904 con Chile y que desmiente el supuesto argumento sobre que Chile forzó a Bolivia a firmar un pacto que lo enclaustraría a perpetuidad (Ostria Trigo, 2008).

\section{Funcionamiento del Tratado de 1904 - 2016: la conectividad hacia el Pacífico}

Cuando Bolivia un siglo más tarde impugna las condiciones dispuestas en el Tratado respecto del libre tránsito, ciertamente obliga a revisar cuánto ha gastado el Estado de Chile en viabilizar, primero la construcción del ferrocarril, la operacionalización de la cláusula del libre tránsito con Bolivia y, luego, la construcción de la carretera de 1993. Esta última 
tuvo un costo de 4.800 millones de pesos y se extiende entre Arica y Chungará, unos 11,8 millones de dólares de la época (MINREL-DIFROL, 1990).

En ese contexto, lo primero que hay que señalar es que el Tratado de 1904 es un "tratado internacional". No constituye un documento político opinable, cuestionable y manipulable políticamente. Ambos países están en la compleja obligación de darle cumplimiento a cabalidad, porque de ello depende la relación fronteriza. Tal como lo expresan la historiadora francesa Françoise Martínez y el historiador boliviano Pablo Quisbert (1999):

El pragmatismo de la política exterior boliviana no se redujo simplemente al hecho de conservar la soberanía. En ambos casos, se logró obtener algo que para los Liberales era muy significativo: la construcción de ferrocarriles. Incluso las compensaciones monetarias estaban destinadas a servir de garantía en los contratos de construcción de líneas férreas en el interior del país. Por tanto, los arreglos diplomáticos se hicieron sobre la fórmula de territorios por ferrocarriles, símbolos de progreso, que en última instancia beneficiaban directamente a la élite exportadora. Por ello, a la hora de los Tratados esta estaba convencida que aún en la derrota, el país lograba beneficios. (1999, p. 4)

La operatividad del Tratado puede ser comprendida en cuatro fases:

1. 1904-1920. Durante los años posteriores a la firma del Tratado de 1904, ambos países construyen los puentes de relación permanente respecto de la materialización de las disposiciones del mismo. Al respecto, se observa la formación de las comisiones de límites, los estudios de los hitos y la colocación de los mismos en frontera. De este tema, ya se tenía cuenta a partir del mes de junio de 1904, cuando el Presidente chileno daba cuenta al Congreso de que ambos países llevaban trabajo adelantado con respecto a las demarcaciones (Riesco, 1 de junio de 1904). Chile asimismo paga 300.000 libras, y materializa la construcción del ferrocarril de Arica a La Paz, inaugurado en mayo de 1913 con 267 millas, de las cuales 128 se construyeron en el lado chileno y 139 en el lado boliviano. De acuerdo con las condiciones técnicas de este ferrocarril, cabe destacar que la sección de cremallera, que fue la parte más compleja del trazado, "pasa por un declive máximo de 6 por ciento y 28 millas aproximadamente, siendo quizás la extensión continua de cremalleras más larga que se ha construido en cualquier parte del mundo" (Riesco, 1 de junio de 1904.). Este hecho no solo explica la demora de la construcción, sino también la dificultad del trazado con 48 puentes, un viaducto, estaciones en Chile y Bolivia y, el extraordinario costo del mismo a raíz de la sección de cremallera que suma un total de 2.865.496 libras, 10 centavos y 13 peniques, casi un millón de libras esterlinas adicionales a los pagados a Bolivia por el territorio del Acre (Decombe, 1913, sic). Ver imagen número 1. 


\section{Imagen $\mathrm{N}^{\circ}$ 1: Trazado del Ferrocarril de Arica a La Paz}

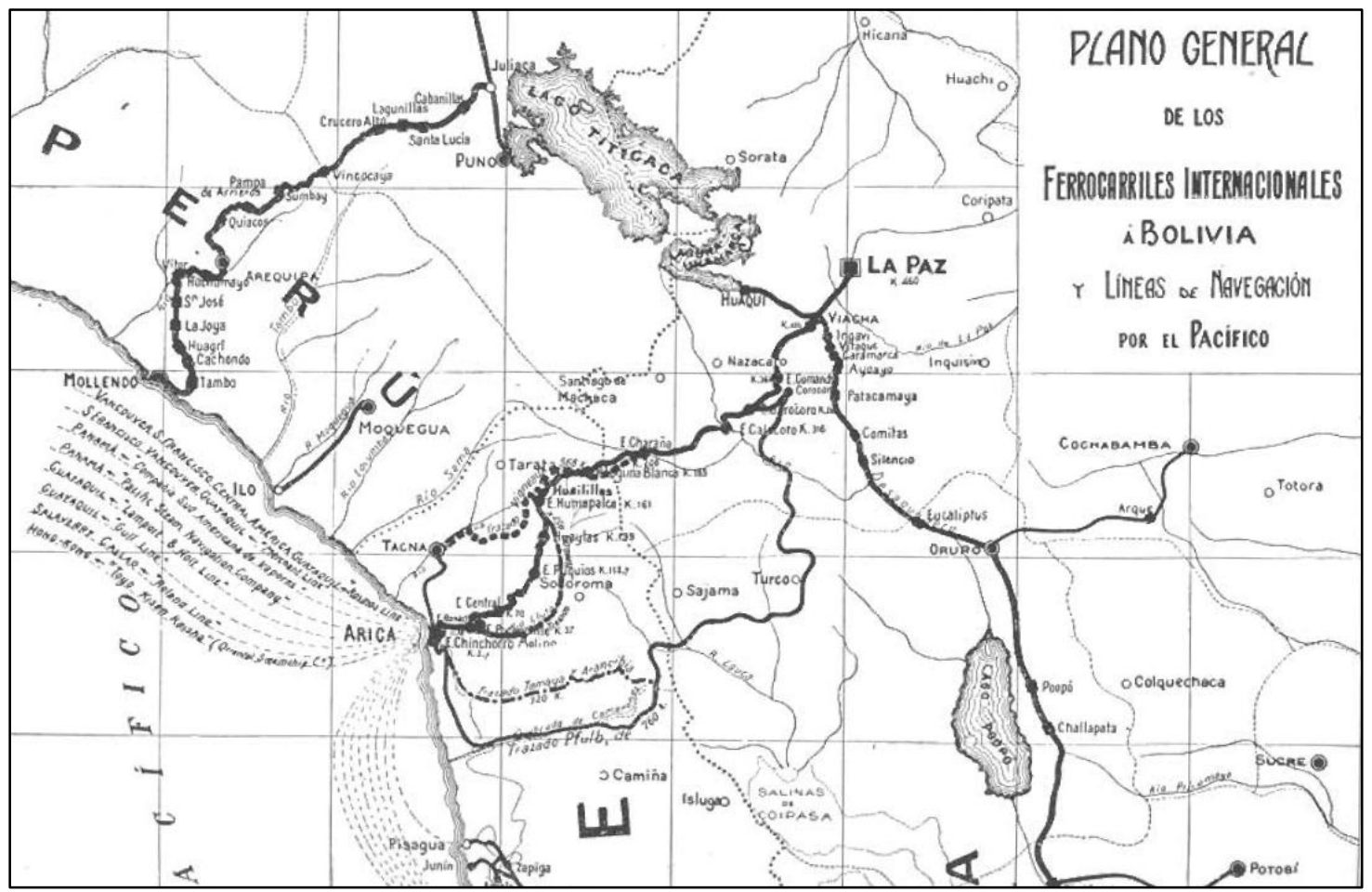

Fuente: Decombe (1913, p. 131).

Entre 1904 y 1920, la dinámica y control del tratado se dieron en las más altas esferas diplomáticas de ambas cancillerías. Sin embargo, para la historiadora española Pilar Jordán García es inédito en la primera década del siglo XX. Era la primera vez que Bolivia tomaba la decisión de explorar exhaustivamente su territorio y el estado de su población (García Jordán, 1998). Este hecho, que en su contexto finalmente termina por valorizar el Oriente boliviano (Memorándum de 1904), deja expuesta la asimetría política interna del país y su contradicción finisecular, a partir del modelo extractivista versus la valoración efectiva del territorio (Molina, Sandoval y Burela, 1904).

La temprana impugnación del Tratado de 1904 -y no así del de Petrópolis- se produce invocando el artículo 19 del Pacto de la Liga de las Naciones. En las consideraciones, no importaron ni los pagos, ni la construcción de ferrocarriles, ni las indemnizaciones y otros. La conclusión final era: es injusto para los intereses de Bolivia. Sin embargo, el rechazo de la causa boliviana de 1921 en la Liga cerró un ciclo. Por un lado, se ratificaba la validez del instrumento jurídico y, por otra, dilucidaba que lo pactado servía perfectamente a los intereses de ambos Estados (Figueroa, 2007). 
2. 1921-1962. Durante este período, el Tratado de Paz y Amistad reguló las condiciones comerciales y portuarias entre ambos países. Las exportaciones bolivianas debieron lidiar con cuatro de los episodios más complejos de la historia contemporánea del país: el declive de la producción del estaño, la crisis económica de 1929, la Guerra del Chaco (1932 -1935) y, finalmente, la Revolución Nacional de 1952. Durante todos estos años y con el tema marítimo en las sombras permanentemente, Chile igual mantuvo operativo los puertos de Arica y Antofagasta y las líneas de trenes.

a. Sin embargo, en 1962, un hecho paralelo a la disputa por el tema marítimo provoca la primera ruptura de relaciones diplomáticas: Bolivia acusa a Chile por el desvío de las aguas internacionales del río Lauca. Pese a esto, los cauces del comercio se mantuvieron tal cual.

3. 1962- 1989. Antes de 1960, los puertos chilenos eran administrados por el Servicio de Explotación de Puertos del Servicio Nacional de Aduanas. Para inicios de los años sesenta, y en un proceso de modernización de la gestión del Estado de Chile, se crea una empresa específica para el manejo portuario. La Empresa Portuaria de Chile (EMPORCHI) fue la encargada de la propiedad, administración, mantención y explotación de los puertos a partir del DLF No 290 de 1960. Según este decreto, los puertos de Arica y Antofagasta quedaron bajo su administración (hasta 1998). Desde una perspectiva comercial, el uso de puertos y el tráfico ferroviario se mantuvieron expeditos. En ese contexto, ni la tensa situación de la diplomacia por el Lauca, o el fracaso de las conversaciones en Charaña en 1975, lograron impedir que miles de toneladas circularan yendo y viniendo de Bolivia a través de los puertos chilenos (Muñoz, 1986).

Así, si en 1962 la carga boliviana que pasaba por el puerto de Arica alcanzaba las 53.326 toneladas, constituyendo el $31 \%$ de la carga total del puerto, al término del gobierno militar se había incrementado a 331.874 toneladas, con casi el $49 \%$ de la participación de la carga transportada por aquel puerto. ${ }^{3}$ Esto demuestra un crecimiento exponencial y flujo permanente de más de 6,2 veces el volumen de la carga del puerto de Arica (DIFROL, 2016). Lo propio ocurría con Antofagasta. Ver Tabla $\mathrm{N}^{\circ} 1$ y Tabla $\mathrm{N}^{\circ} 2$.

3 Esto implicó que, en distintas épocas, en los años 1969, 1975, 1977, 1978 y 1988 la carga boliviana por puerto de Arica, sobrepasara el $50 \%$ del volumen total del puerto. 
Tabla $\mathrm{N}^{\circ}$ 1: Transporte de carga boliviano. Ferrocarril Antofagasta-Oruro

\begin{tabular}{lcccc}
\hline & 1974 & 1975 & 1976 & 1977 \\
\hline Tren de subida & 106.294 & 203.370 & 216.659 & 255.440 \\
\hline Tren de bajada & 109.291 & 119.924 & 137.924 & 174.650 \\
\hline Total & 215.585 & 323.294 & 354.583 & 430.090 \\
\hline
\end{tabular}

Fuente: elaboración propia sobre la base de MINREL (1977).

Lo señalado está refrendado por los 26 acuerdos complementarios suscritos entre Chile entre 1904 y 1955 (MINREL, 1978).

El último informe disponible sobre el libre tránsito boliviano durante el régimen militar data de 1977. Se trata de una separata del MINREL denominada "Facilidades de Libre Tránsito que Chile otorga a Bolivia". Las cifras que entrega el documento dan cuenta de la capacidad portuaria chilena y de la asimetría efectiva del comercio de Bolivia. Al respecto, cabe consignar que "el marcado desequilibrio" era causante ya en 1977 de "un serio problema económico al ferrocarril, ya que una gran proporción de los carros que llevan mercadería a La Paz deben regresar vacíos" (MINREL, 1977, p.12). En este esquema, el diagnóstico chileno era que "el Estado chileno otorga subsidio al comercio exterior boliviano" y que producto de años en estas circunstancias, desde 1959 hasta 1977, se había acumulado una deuda de U\$3.556.000 (MINREL, 1977, p.19).

Tabla $\mathrm{N}^{\circ}$ 2: Importaciones y exportaciones bolivianas a través de puertos chilenos 1974-1977 en miles de toneladas

\begin{tabular}{lcc}
\hline & Importaciones bolivianas & Exportaciones bolivianas \\
\hline 1974 & 81 & 24 \\
\hline 1975 & 90 & 19 \\
\hline 1976 & 61 & 21 \\
\hline 1977 & 75 & 14 \\
\hline
\end{tabular}

Fuente: elaboración propia sobre la base de datos de MINREL (1977). 
4. 1990- 2016. A principios de 1990, con el cambio de gobierno en Chile, el Estado pone especial énfasis en su relación con América del Sur dentro del nuevo contexto ideológico mundial. En efecto, la apertura comercial fue reconocida como un principio fundamental de las democracias occidentales. Así lo comprendieron los gobiernos de Víctor Paz Estenssoro (1985-1989), Jaime Paz Zamora (1989- 1993) y el de Gonzalo Sánchez de Lozada (1993-1997), quienes tuvieron especial acercamiento con Chile, pese a destacar su posición irrenunciable al tema marítimo.

En 1990, cuando asume Patricio Aylwin, DIFROL elabora un documento sobre el acceso a las costas por parte de Bolivia que señala:

Desde un comienzo, este Ministerio propuso la pavimentación de la carretera Arica- Tambo Quemado, como una medida esencial para potenciar la ventajosa situación de Arica como punto de conexión de un extenso y rico sector del interior sudamericano en los mercados de ultramar. (DIFROL, 1990, p. 22)

En este mismo documento, DIFROL agrega: "Pues bien, la carretera se está pavimentando dentro de los plazos que fueron acordados al respecto y se espera finalizar los trabajos, llegando hasta el límite mismo a fines de 1993" (1990, p. 23). La inversión correspondiente alcanzó a 4.800 millones de pesos del año 1993, U\$ 11,87 millones al cambio observado en aquel año. Paralelamente, Bolivia debía hacer su parte de la carretera entre Tambo Quemado y Patacamaya, espacio que finalmente estuvo concluido en 1994.

Un segundo elemento que amplía el cumplimiento del Tratado, y que reconoce un potencial de mejora en la relación bilateral, se especifica con el aumento de las facilidades para el ingreso de los ciudadanos de los países limítrofes, en concreto de Perú y Bolivia. En este asunto, la lógica durante el gobierno militar fue exigir visa a gran parte de los países de la región. Esto claramente ofrecía dificultades para venir a Chile, pero no para transitar si es que se contaba con la documentación necesaria. En el marco del libre tránsito, esta dinámica escasamente contribuía al crecimiento de flujo de personas entre los dos países.

A raíz de ello, en 1992 el Estado de Chile adopta tres acciones concretas para mejorar las relaciones vecinales con Perú y Bolivia:

4 El comentario expone la opción chilena de abrir el comercio a gran parte de Bolivia, pero también con los estados brasileños de Matto Grosso, y el Chaco Paraguayo, así como proyecciones hacia el sur del Perú y el Noreste argentino. En esa lógica, Chile se abre a la noción de país puente hacia Brasil y sitúa a Bolivia, como un país de tránsito obligado entre dos océanos. 
- La supresión de visados para peruanos y bolivianos que ingresaban como turistas.

- La extensión a un año de la validez del salvoconducto para ingresar a Arica desde Tacna. Si bien esta segunda medida opera para Perú, la misma se ampliaría posteriormente para Bolivia.

- Finalmente, y entendiéndose que la paulatina sustitución del tráfico ferroviario por la carretera sería un hecho en el corto plazo, Chile decide mejorar las instalaciones del complejo fronterizo de Chungará, oficina estatal que contaría con alcantarillado y agua potable a 4.200 metros de altura, constituyéndose así juntamente con el complejo de Chacalluta que limita con el Perú, en el segundo más moderno del país (Milet y Rojas, 1999).

\section{El libre tránsito y las acusaciones de Bolivia}

Hay consenso en Chile sobre que, si bien las relaciones chileno-bolivianas han sido de naturaleza conflictiva, desde el retorno a la democracia han constituido una de las prioridades en materia de política exterior. De ello, se deduce la adopción de una estrategia compartida entre 1985-2002, respecto a la idea de conferir mayor la densidad a la relación bilateral más allá del Tratado de 1904 (Maira y Murillo de la Rocha, 2004).

Sin embargo, a comienzos de 2011 hubo un nuevo giro en la dinámica de la relación. El gobierno de Evo Morales decidió crear la Dirección Estratégica de Reivindicación Marítima, Silala y Recursos Hídricos, y anunció su intención de demandar a Chile ante la Corte Internacional de Justicia de La Haya. Desde ese momento, las relaciones presentan un quiebre irrecuperable.

Así, ante la imposibilidad de denunciar el Tratado, desde el 2011 las acusaciones por parte de Bolivia se centran en el mal funcionamiento del tratado, haciendo énfasis en que Chile pone obstáculos respecto del libre tránsito (Montero, 2016).

\section{Controversias en materia de libre tránsito}

¿Existen sin embargo indicios efectivos que el libre tránsito atravesó por obstáculos intencionados por parte de Chile? Hasta antes de la demanda marítima, no particularmente.

En un esfuerzo por dimensionar económicamente los costos del tránsito del comercio boliviano por puertos chilenos, Agramont y Peres Cajías (2016, p. 23) proporcionan un 
análisis sobre cómo evaluar los costos de la mediterraneidad. En esa perspectiva definen que son las características geográficas de los países y la infraestructura con la que cuentan para comerciar sus mercancías lo que determina los costos. Este análisis vuelve a omitir el estudio de campo necesario para comprobar el caso boliviano. Al respecto, los costos deben medirse en tiempo de transporte, porque la variable distancia es inamovible de la ecuación. A saber:

entre el lugar de origen y la aduana nacional; entre la aduana nacional y la aduana del país de tránsito; entre la aduana del país de tránsito y el puerto de tránsito; entre el puerto de tránsito y el destino del producto. (Agramont y Peres Cajías, 2016, p. 40)

Considerando estas variables y la estructura del comercio exterior boliviano se dejan fuera del análisis dos aspectos:

1. Los centros productivos de Bolivia logran sacar sus mercancías; sin embargo, el alto costo que muestran los autores omite la geografía misma del país. Dicho de otro modo, tenga o no acceso soberano a las costas, la distancia es fundamental. En ese contexto, ciertamente la gestión de aduanas es clave, pero a casi 4.000 metros de altura, y tras dos cordilleras, si es que la carga proviene de Santa Cruz, el problema es el mismo: la distancia.

2. El segundo elemento, ¿existe alguna mercadería que no se pueda efectivamente sacar por puertos chilenos? La respuesta es clara: no.

Ya se ha hablado cómo era en fases del siglo XX. La acumulación de evidencia determina que, entre 2015-2018, Bolivia ha logrado instalar 471.401 camiones en la frontera con Chile, a razón de 115 mil por año. Esto implica que las distancias desde los centros de carga boliviana prefieren puertos chilenos que peruanos y que, nuevamente, el problema no es tampoco la infraestructura, sino la distancia. La encuesta citada por Agramont y Peres Cajías (2016) no discrimina si la insatisfacción del comercio internacional es porque la infraestructura chilena o boliviana es deficiente. Sin embargo, lo que sí es posible determinar es que la carga llega a puerto. La Tabla $\mathrm{N}^{\circ} 3$ lo precisa por paso fronterizo y la Tabla $\mathrm{N}^{\circ} 4$, por puerto de destino. 
Tabla $\mathbf{N}^{\circ}$ 3. Ingreso de camiones bolivianos por paso fronterizo y año a Chile

\begin{tabular}{|c|c|c|c|c|c|}
\hline Paso fronterizo & 2015 & 2016 & 2017 & 2018 & $\begin{array}{l}\text { Total por } \\
\text { lugar de } \\
\text { ingreso }\end{array}$ \\
\hline Antofagasta DRA & 8 & 2 & 0 & 0 & 10 \\
\hline Arica DRA & 48 & 14 & 46 & 8 & 116 \\
\hline Cancosa & 1 & 0 & 0 & 0 & 1 \\
\hline Chincolco & 1 & 0 & 0 & 0 & 1 \\
\hline Chungará & 90.232 & 88.782 & 93.743 & 94.096 & 366.853 \\
\hline Colchane & 16.785 & 16.112 & 19.813 & 19.667 & 72.377 \\
\hline $\begin{array}{l}\text { Concordia } \\
\text { Chacalluta }\end{array}$ & 1.099 & 870 & 543 & 270 & 2.782 \\
\hline $\begin{array}{l}\text { Cristo Redentor Los } \\
\text { Libertadores }\end{array}$ & 1.636 & 1.723 & 1.820 & 2.017 & 7.196 \\
\hline El Tránsito & 0 & 0 & 1 & 0 & 1 \\
\hline Huemules & 0 & 1 & 0 & 0 & 1 \\
\hline $\begin{array}{c}\text { Integración Austral } \\
\text { Monte Aymond }\end{array}$ & 4 & 9 & 3 & 0 & 16 \\
\hline Iquique DRA & 13 & 2 & 10 & 4 & 29 \\
\hline Iquique Patio Autos & 0 & 1 & 0 & 0 & 1 \\
\hline Iquique Patio Sellaje & 1 & 1 & 0 & 0 & 2 \\
\hline Jama & 47 & 6 & 3 & 1 & 57 \\
\hline Ollahue & 2.997 & 3.144 & 5.280 & 8.190 & 19.611 \\
\hline Puerto Angamos & 0 & 1 & 0 & 0 & 1 \\
\hline $\begin{array}{c}\text { San Pedro de } \\
\text { Atacama } \\
\end{array}$ & 49 & 37 & 195 & 148 & 429 \\
\hline Visviri & 103 & 479 & 1.276 & 59 & 1.917 \\
\hline TOTALES & 113.024 & 111.184 & 122.733 & 124.460 & 471.401 \\
\hline
\end{tabular}

Nota: el total de los camiones argentinos y peruanos que transitaron por Chile en el mismo período es de 329.562 y el número de camiones con patentes peruanas es de 43.309.

Fuente: elaboración propia sobre la base de registros de la Dirección Regional de Aduanas (2019) 
Tabla $\mathbf{N}^{\circ}$ 4: Ingreso de camiones bolivianos según destino en Chile

\begin{tabular}{|c|c|c|c|c|}
\hline \multicolumn{5}{|c|}{ Por año y destino } \\
\hline & 2015 & 2016 & 2017 & 2018 \\
\hline Arica & 41.407 & 43.282 & 40.111 & 41.987 \\
\hline Iquique & 2.750 & 4.782 & 7.199 & 9.269 \\
\hline Antofagasta & 388 & 874 & 2.054 & 4.170 \\
\hline Chungará & 48.592 & 45.235 & 52.568 & 51.122 \\
\hline Colchane & 13.580 & 11.332 & 12.910 & 10.540 \\
\hline Cristo Redentor & 822 & 411 & 375 & 825 \\
\hline Los Andes & 808 & 1.308 & 1.443 & 1.189 \\
\hline Ollagüe & 2.414 & 1.985 & 2.287 & 2.875 \\
\hline Concordia & 1.137 & 1.985 & 2.287 & 2.875 \\
\hline Iquique Autos & 274 & 129 & 222 & 219 \\
\hline Visviri & 102 & 436 & 1.203 & 60 \\
\hline Chincolco & 12 & 43 & 63 & 47 \\
\hline Puerto Angamos & 6 & 49 & 63 & 37 \\
\hline Sin Información & - & 49 & 63 & 37 \\
\hline TOTAL & 112.292 & 111.900 & 122.848 & 125.252 \\
\hline
\end{tabular}

Fuente: elaboración propia sobre la base de registros de la Dirección Regional de Aduanas (2019).

En retrospectiva, la conclusión preliminar es que Chile no impide el tránsito de camiones, este solo tiende al aumento. Sin embargo, existen problemas y las actas los describen. Las Actas del Comité de Libre tránsito se extienden entre el año 2005 y el 2011. En esta línea de trabajo se consignan las dificultades:

- 2005-2006. La delegación boliviana se queja por la habilitación del puerto de Iquique, argumentando que era un derecho del Tratado de 1904, pero que no se había habilitado como puerto para carga boliviana. A la queja, la delegación chilena respondió que se estaban haciendo los estudios pertinentes para habilitar el 
puerto, en aras de la "fluidez en la cadena de transporte, las características especiales del puerto, su indivisibilidad y competitividad" (Acta de la IV Reunión del Grupo de Trabajo del Libre Tránsito Chile- Bolivia. 28-01-2005). Chile envió una nota reversal, que no fue respondida. La gestión quedó estancada en la Cancillería de Bolivia. Aun así, los comerciantes bolivianos manejan el comercio con Zona Franca (creada en 1975) con todas las facilidades que esta ofrece a partir de esos años. Los otros temas abordados fueron respecto a las tarifas portuarias, trabajos para el almacenamiento de las cargas y la realización de un seminario de cargas peligrosas.

- 2007. Con respecto a la modernización de los puertos, Bolivia manifestó que esa política generaba un impacto negativo en el comercio exterior boliviano, debido a un aumento en las tarifas portuarias, así como por la sustitución del sistema multioperado por un solo operador monopólico. Chile respondió que las concesiones portuarias estaban respetando el régimen internacional. Un segundo reclamo se relacionó con el cobro de parqueo en el Puerto de Arica y, un tercero, apuntó al incremento de tarifas que afectaban el comercio boliviano, que, en opinión de la delegación asistente, atentaban contra el régimen del libre tránsito. De la revisión de las actas, se establece que Chile insistentemente expone la imposibilidad de evitar los cobros de porteo en Arica, explicando la estrechez del espacio en los puertos, y la necesidad de mantener una fluidez en los procesos que conlleva el transporte de carga.

- 2008. Bolivia planteó el incremento de las importaciones bolivianas, llegando a un $80 \%$ del total país a través del puerto de Arica. Nuevamente, alegaba por retardos y costos para los usuarios. La delegación chilena respondió que ello se debía transitoriamente a la modernización del puerto. ${ }^{5}$

- 2009 y 2010. Chile exhibe proyectos de inversión y modernización del puerto de Arica por un valor de U\$ 60 millones, junto con el gasto de U\$ 58 millones por concepto de reposición, rehabilitación y remediación del tramo chileno del ferrocarril de Arica a La Paz (Thomson y Bradanovich, 2015), así como el anuncio de la ampliación de almacenes y del sitio de Atraque $\mathrm{N}^{\mathrm{o}} 7$ de Antofagasta. ${ }^{6}$

- 2005-2011. Momento en el cual se reunieron periódicamente comisiones sobre libre tránsito entre ambos Estados. El tema del libre tránsito fue uno de entre 10 áreas temáticas dispuestas.7 En aquellas donde pudieron haberse manifestado reclamos, como es la económica, no se aprecia mayor complejidad. Sin embargo, sí es importante destacar la cooperación en ámbitos como seguridad y defensa y el fortalecimiento comercial fronterizo. Esas reuniones para negociar y establecer

5 En la práctica, hoy existe un puerto seco de Arica. Este puerto seco se inauguró el 2015, pese a la falta de acuerdos entre los Estados.

6 Thompson y Bradanovic demuestran que estos gastos, sumados al mantenimiento vial, accidentabilidad y otros, son trascendentales en el libre tránsito. 
acuerdos se suspendieron a partir 2011, cuando emergió la reivindicación marítima y la demanda ante la Corte Internacional de Justicia de la Haya. Ver Tabla $\mathrm{N}^{\circ} 5$.

Tabla $N^{\circ}$ 5: Agenda pública de trabajo binacional

\begin{tabular}{ccccccccccc}
\hline AÑO & $\begin{array}{c}\text { Área } \\
\text { Econó } \\
\text { mica }\end{array}$ & $\begin{array}{c}\text { Área } \\
\text { Salud }\end{array}$ & $\begin{array}{c}\text { Área } \\
\text { Coopera } \\
\text { ción }\end{array}$ & $\begin{array}{c}\text { Temas } \\
\text { Fronteri } \\
\text { zos }\end{array}$ & $\begin{array}{c}\text { Medio } \\
\text { ambiente }\end{array}$ & $\begin{array}{c}\text { Área de } \\
\text { cultura }\end{array}$ & $\begin{array}{c}\text { Área } \\
\text { turis } \\
\text { mo }\end{array}$ & $\begin{array}{c}\text { Área } \\
\text { seguri } \\
\text { dad y } \\
\text { defensa }\end{array}$ & $\begin{array}{c}\text { Tema } \\
\text { infraes } \\
\text { tructura }\end{array}$ & $\begin{array}{c}\text { Área } \\
\text { Política }\end{array}$ \\
\hline 2005 & 3 & 3 & 7 & 5 & 1 & & 1 & 2 & 2 & \\
\hline 2006 & 3 & 4 & 4 & 4 & 3 & 3 & 3 & & \\
\hline 2007 & 5 & 4 & 7 & 5 & 4 & 3 & 2 & 3 & 2 \\
\hline 2008 & 2 & 4 & 4 & 4 & 1 & 4 & 1 & 3 & 2 \\
\hline 2009 & 2 & 5 & 10 & 7 & 7 & 5 & 2 & 3 & 2 \\
\hline 2010 & 3 & 7 & 8 & 5 & 5 & 5 & & 1 & 5 \\
\hline 2011 & 4 & 5 & 4 & 3 & 2 & 5 & 1 & 2 & \\
\hline
\end{tabular}

Nota: nótese que no existe un área con el nombre de libre tránsito.

Fuente: elaboración propia sobre la base de Actas del Comité de Frontera y Límites de Chile y

Bolivia. 2005-2011

A nivel de los Ministerios de Relaciones Exteriores, y otros asuntos efectuados en ambos países, hasta el 2011 existieron instancias de diálogo en las que se podían debatir diversos temas y resolver conflictos. La demostración de lo señalado está en los datos recopilados en las Actas del Comité de Fronteras de ambos países. Sin embargo, ¿hubo reclamos sobre libre tránsito? Hubo dos.

1. El realizado por Chile fue sobre el horario de atención de los pasos fronterizos el 2011. Chile solicitó que estos debiesen estar abiertos en horario continuado. Bolivia se comprometió a ello.

2. En el mismo año, la delegación boliviana hizo un reclamo respecto al cerco de fronteras, diciendo que ello no correspondía a una "buena práctica vecinal". La delegación chilena respondió que el "enmallado" - o cerco- era producto del requerimiento de las localidades de frontera.

La Tabla $N^{\circ} 6$ muestra numéricamente la síntesis: 
Tabla $N^{\circ}$ 6: Acuerdos y desacuerdos entre Chile y Bolivia en materia de libre tránsito

\begin{tabular}{cccc}
\hline Año & $\begin{array}{c}\text { Llegan a mutuo } \\
\text { acuerdo }\end{array}$ & Realizan sugerencia & Realizan reclamo \\
\hline $2005-2006$ & 7 & 3 & 1 \\
\hline 2007 & 1 & 2 & 3 \\
\hline 2008 & 4 & 0 & 2 \\
\hline 2009 & 2 & 1 & 0 \\
\hline 2010 & 2 & 2 & 1 \\
\hline 2011 & 0 & 1 & 8 \\
\hline
\end{tabular}

Fuente: elaboración propia sobre la base de actas del Grupo de Trabajo sobre el Libre Tránsito 2005-2011.

Los temas que se trataron preferentemente en estas reuniones fueron la modernización portuaria, la habilitación del puerto de Iquique y la aplicación del régimen del libre tránsito, tarifas portuarias de Arica y Antofagasta, cargas peligrosas (IMO) y cobros de impuestos, entre otros.

En 2011, Bolivia audazmente lamentó que el relacionamiento "se centre solo con un monopolio privado" (MINREL, 2011, p. 1). Este aspecto, que impugna la concesión portuaria a la Empresa Portuaria de Arica, actual administradora del puerto de Arica hasta el 2036, fue esgrimido por Evo Morales en más de una ocasión (América Economía, 21 de septiembre de 2011). La delegación chilena afirmó su sorpresa al respecto, porque Bolivia conocía su funcionamiento desde $1998 .^{8}$ La delegación boliviana, ante los criterios vertidos por la delegación chilena, y considerando que el $90 \%$ de la carga boliviana operaba desde el puerto de Arica, convocó al gobierno de Chile a la "rescisión de la concesión privada monopólica por constituirse una violación al Tratado de 1904” (MINREL, 2011, p.6). El desconcierto de la delegación chilena fue total, por tratarse de un asunto de soberanía estrictamente chilena: "El Embajador Suckel contestó al planteamiento del Embajador Catarina señalando que el reclamo de poner término a la concesión del Puerto de Arica es

8 Las actas de Reunión del Grupo de Trabajo de Libre Tránsito datan del año 2004 y reiteradamente han expuesto su funcionamiento las empresas portuarias de Arica, Iquique y Antofagasta. 
una petición imposible de satisfacer. Ella dura hasta el 2034 y Chile cumple sus compromisos" (MINREL, 2011, p.7)

\section{Conclusiones}

La relación fronteriza y el libre tránsito constituyen una dinámica indisoluble entre Chile y Bolivia. Cuando Bolivia reclama por el libre tránsito, omite que a través de los puertos chilenos se ha manejado todo el volumen de carga hacia el Pacífico por más de 100 años, y que esta ha ido en aumento exponencial en medio de unas relaciones bilaterales extremadamente conflictivas. (Ariñez y Guarachi, 2017). Tomando como base el aumento del volumen de la carga, Bolivia movió durante el 2018 por el puerto de Arica 1.522.972, 8 toneladas más que en 2005. También, en promedio, en estos 11 años el porcentaje de carga boliviana que se ha movido por Arica es el 65,72\% promedio del total que maneja dicho puerto (Memoria EPA, 2015).

Así, entonces, si hasta el 2011 los reclamos efectuados por Bolivia a Chile no se focalizaron en el libre tránsito, ¿qué lleva a impugnar el área? La demanda ante La Haya. Desde entonces hay quejas y se dice que el libre tránsito no funciona, que es muy caro, que las pérdidas para Bolivia son enormes, entre otros argumentos. Bolivia ha enfatizado las acusaciones, al punto de denunciar reiteradamente casos de obstrucción al libre tránsito, cuando en rigor se trata de la instalación de ideas sobre lo que Bolivia "piensa" de cómo Chile debería manejar el tema. Chile y Bolivia mantienen monólogos paralelos en la materia. Bolivia no acepta que el manejo portuario tenga costos y cuestiona las revisiones (Televisión Nacional de Chile, 18 de julio de 2016). Un absurdo y una presión comercial continúa. Chile insiste en que los cobros son de transferencia por el uso del muelle y por el porteo de la carga desde la nave. ${ }^{9}$

Sin embargo, hay que destacar el hecho de que Chile ha ido permanentemente mucho más allá de 1904. En 1993, Bolivia movía apenas 300 mil toneladas. Hoy con una carretera paralela a la línea del tren, transitan casi tres millones de toneladas por año (DIFROL, 2018). Otro tema es que la estructura de las exportaciones bolivianas siga siendo el de materias primas, donde en épocas recientes es el gas el que se lleva el mayor aporte de las exportaciones bolivianas como lo muestran Agramont y Peres Cajías (20161). En consecuencia, las cifras de la carga boliviana que operan por el libre tránsito a través de puertos chilenos son demostrativas del aumento y heterogeneidad, donde además hay que sumar la minería que fundamentalmente sale por el tren de Ferrocarril de Antofagasta (FCAB)y que llega al puerto de Antofagasta. Por lo tanto, la acusación de obstrucción no es válida. Entonces, ¿qué hay detrás de la idea de impugnar el libre tránsito porque aparentemente operaría mal? Dos temas: por un lado, una maniobra política que acompañó

9 En rigor, si el puerto fuera de orden público y no privado, los costos existirían igualmente. 
todo el período de la disputa por la reivindicación marítima. No obstante, también hay que reconocer que sí hay un tema reciente en el que Chile debe poner atención: el costo de las interrupciones portuarias: seis días el 2013; dos semanas el 2014; 12 días el 2015; 20 días el 2016 y nueve días el 2017 (CEBEC-CAINCO, 2018).

Finalmente, las fuentes y estadísticas históricas consultadas en ambos países demuestran que el funcionamiento del libre tránsito ha sido y es una preocupación constante y que, pese a su importancia estratégica, ha tenido menos complejidades que todo el resto de la relación binacional. Tanto las Actas del Libre Tránsito, así como las cifras de comercio, descartan la existencia de obstrucción, sino muy por el contrario, la existencia de una gestión portuaria eficiente y que permite una conectividad efectiva de Bolivia hacia el Pacífico.

\section{Referencias}

Agramont Lechín, D. y Peres Cajías, J. A. (Coords.) (2016). Bolivia un país privado de Litoral. Apuntes para un debate pendiente. La Paz: Oxfam-Plural Editores. Recuperado de https://www.researchgate.net/publication/325541978_Bolivia_un_pais_privado_de_ litoral_Apuntes_para_un_debate_pendiente

América Economía (21 de septiembre de 2011). Bolivia plantea a Chile hacerse cargo de la administración del puerto de Arica. Recuperado de ttps://www.americaeconomia.com/negocios-industrias/bolivia-plantea-chilehacerse-cargo-de-la-administracion-del-puerto-de-arica

Ariñez, R. y Guarachi, A. (6 de julio de 2017). Gonzáles afirma que Heraldo Muñoz usa la tensión Bolivia-Chile para sacar beneficio político. La Razón. Recuperado de http://www.la-razon.com/nacional/Boliavia-Chile-Senado-Gonzales-beneficiadotensiones-bilateral-Munoz_0_2741125883.html

Asebey, R. y Mamani, R. (2015). Violencia y conflicto en la historia de Bolivia. Tinkazos, 18(37), 139-150.

Barragán, R., Lema, A. M., Mendieta, P. y Peres-Cajías, J. (2015). El siglo XX mira al siglo XIX: la experiencia boliviana. En La Historia y la Historiografía en América Latina en el siglo XIX. Perspectivas, configuraciones, itinerarios (Dossier). Memoria Académica, UNLP-FaHCE, № 15.

Becerra de la Roca, R. (2004). El Tratado de 1904 la gran estafa (2da edición). La Paz: Plural.

Bustos, C. (2004). Chile y Bolivia, un largo camino. Santiago: RIL-ADICA.

Cambio (17 de octubre de 2016). Evo: Bolivia pierde 2,7\% de PIB por año, casi \$US 1.500 millones. Cambio. Recuperado de http://www.cambio.bo/?q=node/15232 
Flores Gallegos, A. y Mollinedo, J. E. (2012). Análisis comparado para las exportaciones bolivianas a través de los puertos de Iquique y Arica. La Paz: Cámara Nacional de Despachantes de Aduana e Instituto de Comercio Exterior y Aduanas.

Carrier, A., Téllez, E. y Villamizar, F. (2013). Solución a la mediterraneidad de Bolivia: una propuesta desde Chile. Revista de Relaciones Internacionales, Estrategia, y Seguridad, 8(1), 235-266.

CEBEC-CAINCO (2018). En el corazón de Sudamérica. Las alternativas frente a la mediterraneidad. Revista Empresa y Desarrollo, 159, 20-45. Recuperado de https://issuu.com/empresaydesarrollo/docs/eyd_octubre2018

Ceppi, N. (2014). La política exterior de Bolivia en tiempos de Evo Morales Ayma. Si Somos Americanos, 14(1), 125-151.

Coloma, C. (2012). Las relaciones entre Chile y Bolivia tras el anuncio del gobierno boliviano de demandar a Chile ante un tribunal internacional. Revista Política y Estratégica (ANEPE), 119, 131-169.

Concha Robles, J. M. y Garay Vera, C. (2013). El Tratado de 1904. Negociaciones e intereses involucrados. La Paz: Plural Editores.

Correa, L. (2007). "El proceso de integración cultural entre Chile y Bolivia: Desde su historia, sus perspectivas y desafíos". En M. Artaza y P. Milet (Editores), Nuestros vecinos. (pp. 257-282). Santiago: RIL.

Correa, L. (2012). La política exterior de Chile hacia Bolivia 1990-2009: desde la ignorancia mutua a la construcción de una agenda común. En M. Artaza y C. Ross (Eds.), La política exterior de Chile, 1990-2009 (pp. 581-635). Santiago: RIL.

Correa, L. y García, V. (2013). Turbulencias desde el mar: Chile y Bolivia. Si Somos Americanos, 13(1), 93-121.

Correa, L. y Vera, L. (2016). La disputa por el mar: el soft power boliviano ante organismos multilaterales (2006-2013). Revista de Relaciones Internacionales, Estrategia y Seguridad, 11(1), 263-286.

Decombe, A. (1913). Historia del Ferrocarril de Arica a La Paz. Santiago: Ministerio de Industria y Obras Públicas de Chile.

Díaz, V. (2011). Breve historia de la minería en Bolivia. Cochabamba: Petropress.

Dirección Nacional de Fronteras y Límites del Estado (DIFROL). (1993). Carretera AricaTambo Quemado. Archivo General Histórico. Ministerio de Relaciones Exteriores. Módulo 2. Chile-Bolivia. 1973-1993.

DIFROL. (2005). Acta de la IV Reunión del Grupo de Trabajo del Libre Tránsito ChileBolivia. 28-01-2005, Iquique. Solicitado a Anselmo Pommes, Director de DIFROL.

DIFROL. (2016). Datos de carga boliviana por puerto de Arica proporcionados por el Director de Fronteras, Sr. Anselmo Pommes, 18 de enero.

DIFROL. (2018). Datos proporcionados por el Director de Fronteras, Sr. Anselmo Pommes, 10 de junio. 
Dirección Regional de Aduanas. Sistema de Registro de Operaciones de Transporte Terrestre. Dirección Regional de Aduanas. [Información solicitada en forma personal a la Institución a través de Ley de Transparencia. Fecha proceso: 28 de marzo de 2019].

Dirección Regional de Aduanas. Sistema de Registro de Operaciones de Transporte Terrestre. Dirección Regional de Aduanas. [Información solicitada en forma personal a la Institución a través de Ley de Transparencia. Fecha proceso: 08/04/2019].

DIREMAR (2014). El libro del mar. (Segunda Edición Revisada). La Paz: Ministerio de Relaciones Exteriores de Bolivia.

El Comercio de Bolivia (16 de diciembre de 1903). El Tratado con el Brasil. Legación de Brasil en Bolivia. Archivo de Itamaraty. Legación de Brasil en La Paz, Carpeta 1903-1907. Anexo oficio sección $2^{\circ} \mathrm{N}^{\circ} 27,16$ de diciembre de 1903, nota de prensa 4, p. 2.

Empresa Portuaria de Arica (EPA). (2015) Memoria 2015. Arica.

Figueroa, U. (2007). La demanda marítima boliviana ante los foros internacionales. Santiago: RIL.

García Jordán, P. (1998). Fronteras, colonización y mano de obra indígena en la Amazonía Andina. (siglo XIX y XX): la construcción del espacio socioeconómico en Ecuador, Perú y Bolivia. (1742-1848). Lima: Fondo Editorial PUCP.

García Pinzón, V. (2015). Territorios fronterizos. Agenda de seguridad y narcotráfico en Chile: el Plan Frontera Norte. Estudios Internacionales, 47(181), 69-93.

Gómez Zubieta, R. (2001). Políticas de transporte ferroviario en Bolivia. 1860-1940. En D. Cajías, M. Cajías, C., Johnson y I. Villegas, I. (eds.), Visiones de fin de siglo. Bolivia y América Latina en el siglo XX (pp. 367-387). La Paz: IFEA, disponible en: https://books.openedition.org/ifea/7273

González Mansilla, C. (2015). Las facilidades con las que cuenta Bolivia para acceder al mar. Revista Marina REVISMAR, (2), 32-39.

Ovando Santana, C. y González Miranda, S. (2014). La relación bilateral chileno-boliviana a partir de las demandas tarapaqueñas: aproximación teórica desde la paradiplomacia como heterología. Estudios Internacionales, 46(177), 35-64.

González Miranda, S. y Ovando Santana, C. (2016). "Emotivistas" bolivianos en la relación diplomática entre Bolivia y Chile en torno a la mediterraneidad. Estudios Internacionales, 48(183), 39-65.

González Ortega, N. (2017). Bolivia en su historia y literatura, 1920-1982: del Estado republicano a la Revolución de 1952 y sus efectos en el nuevo orden democrático de 1982. En N. González Ortega (Ed.), Bolivia en el siglo XXI (pp. 43-66). Frankfurt a. M., Madrid: Iberoamericana Vervuert.

Guzmán Escobari, A. (2015). Un mar de promesas incumplidas. La Paz: Plural Editores. 
Hasenclever, A., Mayer, P. y Rittberger, V. (1999). Las teorías de los regímenes internacionales: situación actual y propuestas para una síntesis. Foro Internacional, 39(4), 499-526.

IBCE (2012). Terminal Puerto Arica-TPA al servicio del comercio exterior boliviano. Comercio Exterior, 21 (206). Santa Cruz: Instituto Boliviano de Comercio Exterior.

IBCE (2016). Cifras del comercio exterior boliviano 2016. Comercio Exterior, 25 (249). Santa Cruz: Instituto Boliviano de Comercio Exterior.

Krasner, S. (1983). International Regimes. Nueva York: Cornell University Press.

Lagos, G. (2013). La aspiración marítima de Bolivia. Estudios Internacionales, 45(176), 99-134.

Maira, L. y Murillo de la Rocha, J. (2004). El largo conflicto entre Chile y Bolivia-Dos visiones. Santiago: Editorial Taurus.

Martínez, F. y Quisbert, P. (1999). Resignación y ambición: la política exterior liberal. Bajo la lupa. La Guerra Federal. Fascículo 12. La Paz: Ed. La Razón-Coordinadora de Historia.

Milet, P. y Rojas Aravena, F. (1999). Chile- Perú, ¿camino hacia la confianza o la tensión? Santiago: Nueva Serie FLACSO: Relaciones Internacionales y militares.

Ministerio de Relaciones Exteriores de Chile- MINREL (1977) Facilidades de Libre Tránsito que Chile otorga a Bolivia. Santiago: MINREL

MINREL (1978). Tratados, convenciones y arreglos internacionales de Chile, 1810-1976: relaciones bilaterales Chile-Bolivia. Santiago: MINREL.

MINREL-DIFROL (1990). Informe de la carretera Arica- Tambo Quemado. Archivo General Histórico. Módulo 2. Chile Bolivia 1973- 1989.

MINREL. (2011) Acta de la XII Reunión del Grupo de Trabajo sobre Libre Tránsito Bolivia- Chile.

Molina, S. (2014). Cuadrar el círculo: las propuestas de solución al conflicto entre Chile y Bolivia. Santiago: LOM.

Molina, P., Sandoval, A. y Burela, J. (1904) Memorandum de 1904. Santa Cruz.

Montero, B. (23 de septiembre de 2016). Evo denuncia a Chile ante la ONU por atropellos al libre tránsito y violación de DDHH. La Razón. Recuperado de http://www.larazon.com/index.php?_url=/nacional/Bolivia-Chile-DDHH-Arica-puertos-denunciaEvo_0_2569543030.html

Muñoz, H. (1986). Las relaciones exteriores del gobierno militar chileno. Santiago: Prospel- CERC-Las Ediciones del Ornitorrinco.

Orías, R. (2004). Bolivia-Chile: la cuestión de la mediterraneidad. Algunas consideraciones desde el Derecho Internacional. Fuerzas Armadas y Sociedad, 18(1-2), 51-73. 
Orías, R. (2015). La demanda marítima de Bolivia en La Haya entre el pacta sunt servanda y la promisio est servanda. La balsa de piedra, 10, 1-14.

Ostria Trigo, M (2008). El tratado boliviano-chileno de 20 de octubre de 1904. Revista Boliviana de Derecho, 6, 57-70.

Ovando, C. (2015). La noción de soberanía en las propuestas bolivianas para la salida al mar: el caso Arica trinacional. Diálogo Andino, 48, 127-138.

Quitral Rojas, M. (2014). Encierro geográfico boliviano: cuatro hipótesis para entender esta condición, 1970-1990. Revista Internacional de Investigación en Ciencias Sociales, 10(2), 181-196.

Riesco, G. (1904). Mensaje del 1 de junio del Presidente de Chile al Congreso Nacional. Santiago: Imprenta Nacional. Disponible en Memoria Chilena. http://www.memoriachilena.gob.cl/602/w3-article-85752.html

Rodríguez Elizondo, J. (2009). De Charaña a la Haya: Chile, entre la aspiración marítima de Bolivia y la demanda marítima de Perú. Estudios Internacionales, 42(163), 151-161.

Ríos Gallardo, C. (1963). Chile y Bolivia definen sus fronteras. 1842-1904. Santiago: Editorial Andrés Bello.

Ruz, M. I. (2011). Relaciones Chile- Bolivia. En J. Ensignia, C. Fuentes y M. Fernández, M. (Eds.). Política exterior en el Chile postconcertación: ¿quo vadis? (pp. 155162). Santiago: Fundación Ebert-Stiftung y Fundación Chile 21.

Salas, A. (2015). El fenómeno de la droga en el norte de Chile. Una amenaza creciente a la seguridad. En L. Correa, y A. Salas, Gobernabilidad, desarrollo y seguridad en las zonas extremas de Chile (pp. 277-315). Santiago: ANEPE.

Schmitt, C. (2007). The Concept of the Political. Chicago: University of Chicago Press.

Soux, M. L. (1999). Cara y Cruz de la modernidad liberal. Historias Bajo la Lupa. La Guerra Federal. Fascículo 12. La Paz: Ed. La Razón-Coordinadora de Historia.

Tapia, M. y Chacón, F. (2016). Vínculos transfronterizos: vida, movilidad y comercio en el barrio boliviano de Iquique, Chile. REMHU. Revista Interdisciplinar da Mobilidade Humana, 24(47), 131-152.

Televisión Nacional de Chile (18 de julio de 2016). Choquehuanca tras visita a Puerto de Arica: "Chile no respeta la declaración de 1953". 24 Horas [Noticiero televisivo]. Recuperado de http://www.24horas.cl/nacional/choquehuanca-tras-visita-a-puertode-arica-chile-no-respeta-la-declaracion-de-1953-2078237

The Kew Gardens Archives (1902). "Carta del Marqués de Landsdowne al Foreign Office del Imperio Británico", 28 de enero. FO 11/39, Londres.

Thomson, I. y Bradanovich, T. (2015). Costos para la Región de Arica y Parinacota incurridos por el cumplimiento del tratado de paz y amistad de 1904 y otras facilidades concedidas por Chile a Bolivia. Estudios Internacionales, 47(182), 79103. 
Thorp, R. (1998). Progress, Poverty y Exclusion. An Economic History of Latin America in the 20th Century. Washington D.C.: BID-UE-John Hopkins University Press.

Yacsic, F. (1997). Bolivia, modernizaciones empobrecedoras. La Paz: Muela del Diablo Ediciones. 